\title{
The position of a duodenal diverticulum in the area of the major duodenal papilla and its potential clinical implications
}

\author{
E. Jakubczyk¹, M. Pazurek², A. Mokrowiecka², B. Woźniak², E. Małecka-Panas²,

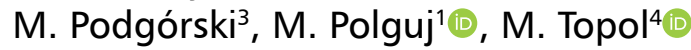

'Department of Normal and Clinical Anatomy, Chair of Anatomy and Histology, Medical University of Lodz, Poland 2Department od Digestive Tract Diseases, Chair of Gastroenterology, Medical University of Lodz, Poland ${ }^{3}$ Department of Diagnostic Imaging, Polish Mother's Memorial Hospital - Research Institute, Lodz, Poland ${ }^{4}$ Department of Angiology, Chair of Anatomy and Histology, Medical University of Lodz, Poland

[Received: 15 August 2019; Accepted: 7 January 2020]

Background: Although duodenal diverticula are associated with less frequent pathology than the colonic diverticula in the large intestine, their periampullary position may have significant clinical implications. The aim of the study was to identify any possible correlation between the type of localisation of the major duodenal papilla, duodenal diverticula, and some particular clinical issues.

Materials and methods: In total, 628 patients (408 females and 220 males; aged 21-91 years), who underwent endoscopic retrograde cholangiopancreatography were included in this study. The patients were divided into two groups: a study group comprising 66 (10.5\%) patients with periampullary position of diverticula (group A), and a control group comprising 562 (89.5\%) patients without diverticula (group $B$ ).

Results: A duodenal diverticulum was diagnosed in the periampullary position in 66/628 (10.5\%) patients: 41 women (aged 52-91 years) and 25 men (aged 54-83 years).

Conclusions: Three types of localisation were observed for the major duodenal papilla with regard to the diverticula, with the most common type being next to each other (type III). In patients with diverticula, similar frequencies of gallstone occurrence are observed in men and women. Patients with papilla in the diverticulum who underwent cholecystectomy are more prone to develop lithiasis. (Folia Morphol 2021; 80, 1: 106-113)

Key words: endoscopic retrograde cholangiopancreatography (ERCP), duodenal diverticula, choledocholithiasis, major duodenal papilla

\section{INTRODUCTION}

Diverticula of digestive tract are usually seen in the large intestine. They form "baggy intestine pouches" extending beyond the colonic wall. Diverticula have been shown to develop in response to increased pressure inside the intestinal lumen, weakness of the muscular membrane of intestine, a fibre-deficient diet, low physical activity and chronic constipation. Furthermore, the incidence of diverticula increases with age [4, 21]. Two types of diverticulum have been recognised: true diverticula, caused by developmental disorders following the deformation of all layers of the intestine wall, and spurious diverticula, formed only by the mucous and submucous membrane; the 
latter resemble hernias and develop in spots with decreased wall resistance $[19,21]$.

Duodenal diverticula (DD) are less frequently seen but are of significant importance, especially when they are located in close proximity to the major duodenal papilla (MDP). They are the second most common morphological pathology of the digestive tract after the colonic diverticula. This common entity was first described by Chomel in 1710 [see 32]. Their prevalence in particular populations ranges from $5 \%$ to $32.8 \%$ and has no sex predilection [3, 4, 19-21, 29, 32].

Duodenal diverticula are usually detected incidentally in patients during endoscopic retrograde cholangiopancreatography (ERCP) $[4,12,15,18,24$, $25,34,41,43]$. Congenital or true diverticula are rare, contain all layers of the duodenal wall, and may be subdivided into intraluminal and extraluminal forms [17, 32]. Intraluminal DD, first observed by Silcock in an autopsy specimen in 1885 , are postulated to be secondary to congenital webs or membranes formed during the recanalization stage of the duodenal lumen after the seventh week of gestation incomplete canalisation of the lumen. Extra-luminal duodenal diverticulum is a herniation acquired from a defect in the bowel wall due to entrance of vessels. The diagnosis in the literature has been almost exclusively based on the pathognomonic a barium-filled sac surrounded by a narrow radiolucent line entirely within the duodenum. The acquired or false type is more common, and is formed by protrusion of the mucosa, muscularis mucosa, or submucosa through a focal weakness in the duodenal wall. This is usually near blood vessels, the pancreatic duct, and the common bile duct [17, 32]. Spurious DD are mainly found next to the major duodenal ampulla, where they are associated with the healing of ulcerations in this area [20].

Duodenal diverticula are typically observed in patients older than 40 years old and their frequency increases with advancing age. Their formation is associated with the progression of duodenal motility disorders. The main underlying aetiologies for this defect are believed to be increased intraduodenal pressure and the progressive weakening of the intestinal smooth muscles. Diverticula are frequently asymptomatic, but they may be a cause of considerable morbidity $[6,14,15,32,33]$.

Duodenal diverticula rarely cause any specific symptoms. A feeling of fullness or nausea may appear, as well as postprandial pain related to the stretching of the large diverticula by the lingering chyme. These symptoms are often mistaken with signs of peptic ulcer disease [6]. However, DD may be of major clinical importance, especially when they are located close to the MDP $[22,24]$. A few reports have proposed an association between the position of the MDP in the diverticulum and an increased frequency of bile duct disease, especially lithiasis and pancreatitis $[3,4,9,16,18,19,21,36,38,39]$.

Although DD are usually asymptomatic and discovered incidentally in patients during ERCP, DD can be associated with various pathological conditions such as common bile duct obstruction, pancreatitis, perforation, bleeding, and in rare cases, carcinoma $[1-3,8,27,30]$.

The aim of the study was to evaluate the frequency of MDP in the duodenal diverticulum with regard to diverticula characteristics, patient demographics, and the frequency of bile duct lithiasis, as well as of other pathologies or specific complaints. This data was approved by the ethics committee of the Medical University of Lodz (NR RNN/186/12/ KE).

\section{MATERIALS AND METHODS}

This study was designed in a retrospective manner. Initially, 650 adult patients (421 women and 229 men), hospitalised in the Department of Digestive Tract Diseases Medical University of Lodz between 2010 and 2014 were evaluated for inclusion in the study. All individuals underwent an ERCP due to the following medical indications: clinical and biochemical features of jaundice, bile duct inflammation, severe gallstone, pancreatitis and suspected malignancy of the MDP, biliary ducts or pancreas, as in other hospitals $[4,10,29]$. Other indications in this group were based on previous ultrasonography and computed tomography examinations.

Twenty-two patients were excluded from the evaluated group because of cholangiocarcinoma and pancreatic cancer. Finally, 628 patients (408 women and 220 men), aged 21-91 years were included in the study (Table 1). Written informed consent was obtained from all patients who underwent ERCP.

During ERCP, the duodenal papilla was identified and catheterised. The bile duct was contrasted with a non-ionic contrast agent (Ultravist) and an X-rh ERCPay image was taken.

Among patients diagnosed with ERCP, the presence of stones in the biliary ducts or/and concre- 
Table 1. Demography of examined patients

\begin{tabular}{lccccccc}
\hline Gender & \multicolumn{4}{c}{ Demography } \\
\cline { 2 - 4 } & \multicolumn{3}{c}{$\begin{array}{c}\text { Patients with } \\
\text { diverticulum }\end{array}$} & & \multicolumn{3}{c}{$\begin{array}{c}\text { Patients without } \\
\text { diverticulum }\end{array}$} \\
\cline { 2 - 3 } \cline { 6 - 8 } & N & $\%$ & BMI & & N & $\%$ & BMI \\
\hline Female & 41 & 62.1 & $31 \pm 0.5$ & & 367 & 65.3 & $30 \pm 0.5$ \\
Male & 25 & 37.9 & $29 \pm 0.5$ & & 195 & 34.7 & $27 \pm 0.5$ \\
Total & 66 & & & & 562 & & \\
\hline
\end{tabular}

$\mathrm{BMI}$ - body mass index

tions in the gallbladder was recognised as primary choledocholithiasis; however, among those who had undergone cholecystectomy, choledocholithiasis in the biliary ducts was recognised as secondary [29].

The duodenal diverticulum was diagnosed as a depression of the intestine mucous membrane deeper than $5 \mathrm{~mm}$.

The study population was divided into two groups: a study group comprising 66 patients $(10.5 \%$ of the initial group) with periampullary position of diverticula (group A), and a control group comprising 562 (89.5\%) patients without diverticula (group B).

The classification proposed by Boix et al. [4] was used to estimate the position of the duodenal major papilla in patients with the diverticula in the periampullary position. Three localisation types were identified for the major duodenal papilla: type I - MDP situated inside a diverticulum (centrally or at its internal edge), type II - MDP located between two diverticula, and type III - MDP situated $3 \mathrm{~cm}$ from a diverticulum, or at its external edge. All incidences were classified as type I, II or III, and the results for group A were compared with those for group $B$ at ERCP.

\section{Statistical analysis}

Statistical analysis was performed using Statistica 12.0 software (Statsoft, Cracow, Poland). P $<0.05$ was considered significant. The $\chi^{2}$ test was employed to compare nominal data between two groups of patients divided according to the presence of a duodenal diverticulum.

\section{RESULTS}

\section{Patient characteristics}

Among 628 examined patients, the presence of at least one diverticulum in the area of the MDP was detected in 66 patients, and these were assigned to group A (10.5\%). Within group A, $41(62 \%)$ subjects were women, aged $52-91$ years, and 25 (38\%) were

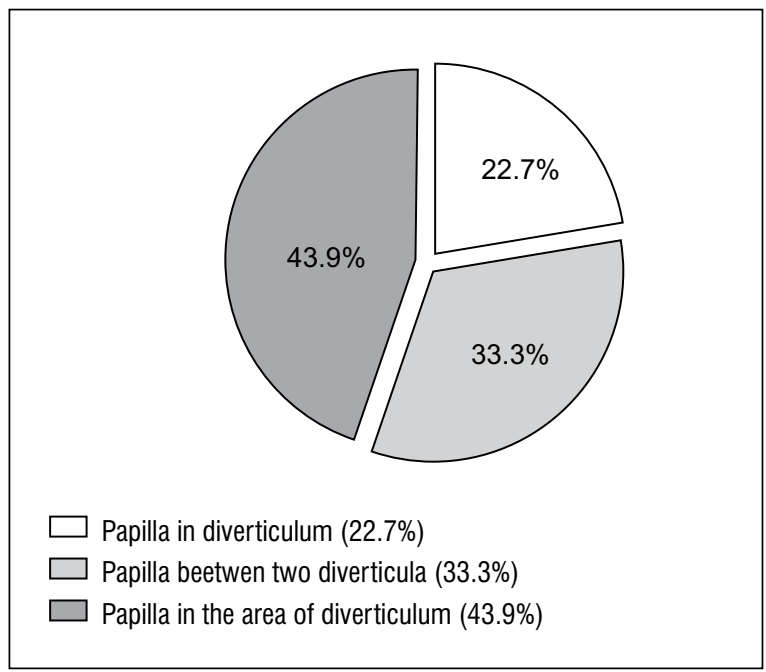

Figure 1. Location of major duodenal papilla in the area of the diverticulum.

men, aged 54-83. Similarly, in group B were $367 / 562$ (65.3\%) women and 195/562 (34.7\%) men. The difference between the number of women in group $A$ and $B$ was not significant $(p=0.6083)$. The majority of patients in group A (84.8\%) and B (81.9\%) were over the age of 60 . The difference between these patients of the two groups was not significant ( $p=0.5416)$.

\section{DD and MDP}

Of the MDP localisations, the most common was type III, i.e. where the MDP was situated next to the diverticula or at its external edge, which was observed in 29/66 cases (43.9\%). This was followed by type II, i.e. where the MDP was located between two diverticula, observed in 22/66 cases (33.3\%), and then type I, i.e. where the MDP was situated inside of the diverticula, in 15/66 cases (22.7\%). Types II and III together were named as the juxtapapillary positions of the MDP (Fig. 1).

Juxtapapillary MDP was present significantly more often in woman $(28 / 41 ; 68.3 \%)$ than in men $(9 / 25$; $36 \% ; p=0.002$ ). No significant difference in diverticulum location was observed with regard to age $(p=0.3486)$.

\section{DD and clinical considerations}

In 38/66 (57.5\%) patients with diverticulum, biliary stones were detected with ERCP, and were removed during the same procedure. Only in 1 case was the size of the bile stone too large to be removed and the patient referred to surgery. Bile duct stones occurred less frequently in group B $(262 / 562 ; 46.6 \%)$ than in 
group A (38/66; 57.5\%); however, the difference was not significant ( $p=0.0918$; Fig. 2 ).

Biliary lithiasis was therefore detected in 262 cases in patients without diverticula: 192/367 (52.3\%) women and 70/195 (35.9\%) men. In this group, the frequency of choledocholithiasis was significantly higher in women then in men ( $p=0.002)$.

In contrast, no such significant difference in biliary lithiasis frequency was observed between male and female participants with the duodenal papilla located near the diverticulum: $25 / 41(60.9 \%)$ women vs. $13 / 25(52 \%)$ men $(p=0.646)$.

Primary choledocholithiasis was detected in $28 / 66$ (33.3\%) patients of the whole of group A, and in $240 / 562(42.7 \%)$ of the whole of group B $(p=0.1536)$. However, among the patients with lithiasis, 28/38 (73.6\%) from group A and 240/262 $(91.6 \%)$ from group $B$ suffered from primary choledocholithiasis. The difference between these groups was statistically significant ( $p=0.0115)$.

Of the patients with choledocholithiasis, additional gallbladder stones were detected in $4 / 28(14.3 \%)$ in group $A$, and $36 / 240(15 \%)$ in group $B$.

Secondary choledocholithiasis was found in 10 patients from group $A$ and 10 (26.3\%) with lithiasis. In group B, it was identified in 22 of all 562 (3.91\%) patients or 22 of the 262 (8.4\%) patients with lithiasis. The difference between these groups was significant $(p=0.0184)$.

\section{DD and clinical complications}

A small number of complications such as bleeding were observed in the elderly patients $(3 / 66 ; 4.5 \%)$. Pancreatitis was not observed.

Of the 66 patients with duodenal diverticulum, $12(18.7 \%)$ individuals required prosthesis implantation into bile ducts due to incomplete stone evacuation. Among the 562 patients with the major duodenal papilla in the normal position, $141(25 \%)$ required the prosthesis. The difference was not significant ( $p=0.291$; Fig. 3).

Similar proportions of patients from group $A$ (40/66 subjects; $60.6 \%)$ and group B (333/562 subjects; $59 \%)$ underwent endoscopic papillotomy $(p=0.8323 ;$ Fig. 4).

In 21 of the 66 (42.2\%) examined patients with diverticula, no other pathology was detected. It can be assumed that symptoms like pain and jaundice in this group were only caused by the presence of diverticula. However, the type of position of the diver-

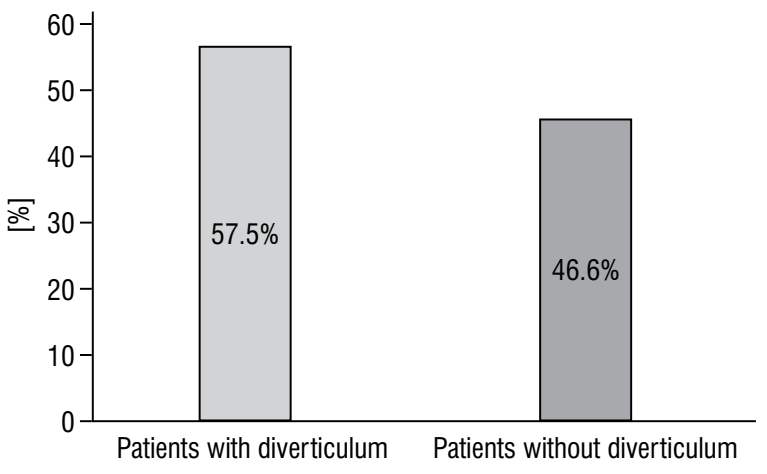

Figure 2. Frequency of lithiasis in patients with diverticulum, and in patients without diverticulum.

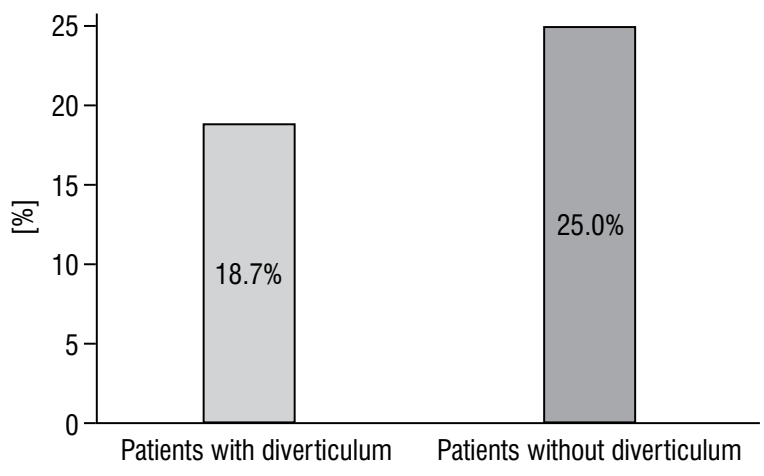

Figure 3. Frequency of prothesis of the bile duct.

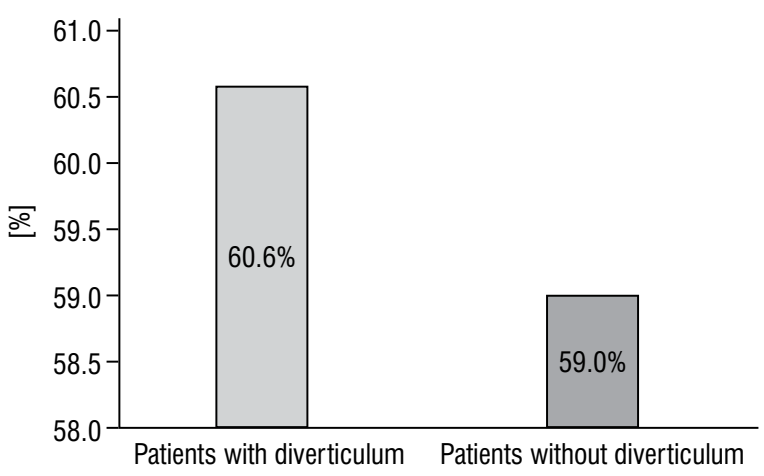

Figure 4. Frequency of endoscopic papillotomy.

ticulum was not connected with increasing frequency in any specific complaints.

\section{DISCUSSION}

The incidence of DD ranges between $5 \%$ and $32.8 \%$ with the most common localisation being in the area of the MDP $[4,10,20,26]$. Boix et al. [4] reports the frequency of periampullary diverticulum to be $32.8 \%$, while Zoepf et al. [44] reports $12 \%$, which is similar to our findings. 
Table 2. The three types of papilla's location with respect to periampullary diverticula

\begin{tabular}{lcccc}
\hline Authors & Total (n) & Type I (\%) & Type II (\%) & Type III (\%) \\
\hline Boix et al. [4] & 131 & $49 \%$ & $30.5 \%$ & $19.8 \%$ \\
Chandy et al. [7] & 200 & $14 \%$ & $17 \%$ & $70 \%$ \\
Katsinelos et al. [15] & 107 & $14 \%$ & $72 \%$ & $14 \%$ \\
Ozogul at al. [31] & 249 & $41.3 \%$ & $41.7 \%$ & $17 \%$ \\
Yildirgan et al. [41] & 51 & $52 \%$ & $37.3 \%$ & $9.8 \%$ \\
Zippi et al. [43] & 77 & $28.6 \%$ & $46.7 \%$ & $24.7 \%$ \\
Present study & 66 & $22.7 \%$ & $33.3 \%$ & $43 \%$ \\
\hline
\end{tabular}

The prevalence of DD increases with patient age. Our present findings indicate the majority of patients with duodenal diverticulum to be over 60 years old, which is confirmed by previous studies [21, 26, 29, 31 ]. Accordingly, roughly $40 \%$ of DD cases were found in patients aged 70 to 79 years $[4,7,10,37]$. This relationship with advancing age suggests a degenerative process involving local supporting structures as an additional factor in the pathogenesis of DD [10]. This process may interfere with biliary drainage by establishing an unfavourable pressure gradient across the biliary tracts or by contraction of the duodenal wall and bile duct sphincter, thus obstructing the flow $[10,12]$. In the case of secondary inflammation, the common bile duct can be obstructed by a juxtapapillary duodenal diverticulum filled with a food bezoar [24]. In turn, this may contribute to stasis in the biliary and pancreatic ductal systems, thereby promoting infection and increasing lithiasis [10, 23]. In most cases, DD are asymptomatic and are detected only by chance during ERCP examination [4, 19, 25, 28]. However, when symptoms occur, they often coexist with pathology in the hepato-pancreatic area.

Many authors consider DD to be a risk factor for choledocholithiasis and relapsing lithiasis $[4,8,9,11$, $14,18,21,25,29,40,42]$. Lithiasis tended to occur more frequently among patients with DD than in patients with the major duodenum in normal location. There are only a few reports on the role of diverticula in the pathogenesis of choledocholithiasis [3, 11, 19, 22,33 ]. However, several hypotheses have been put forward to explain the observed higher incidence of biliary stone formation in the presence of DD. First, it was proposed that dysfunction in the sphincter of the common bile duct can lead to lithiasis by causing the reflux of pancreatic fluid and intestinal content. Second, it is possible that diverticula cause the sphincter to spasm, thereby increasing biliary duct pressure that may in turn produce jaundice and cholangitis, as well as increase the chance of biliary stone formation. Finally, DD can compress the distal part of the common bile duct, causing functional biliary stasis $[2,5,35]$.

Our present findings indicate a correlation between gender and choledocholithiasis only in the control group. In the study group, the frequency of lithiasis was similar in both sexes. The most common location of MDP in relation to the diverticulum was type III (43.9\%), which is inconsistent with the reports of other authors (Table 2).

However, our findings are only confirmed by those of Zippi et al. [43]. So, the present study revealed that published data on the prevalence of papilla location with respect to DD is contradictory. This may be due to differences in the criteria used for classifying the position of the duodenal papilla and DD. For example, in contrast to all other articles, Katsinelos et al. [15] define type III as the intradiverticular position, i.e. papilla located between two adjacent diverticula $[4,7,15,31,41,43]$.

In our research, bile duct stones occurred less frequently in group $B$ than in group $A$; however, the difference was not significant $(p=0.0918)$.

Primary choledocholithiasis was detected less frequently in patients from group $A$ than from group $B$ $(p=0.1536)$. However, a significantly greater proportion of the patients with lithiasis from group $A$ (73.6\%) suffered from primary choledocholithiasis than from group $B(p=0.0115)$. Various other studies, including Tham and Kelly [37], report the greatest percentage to be among patients in whom choledocholithiasis was accompanied by cholecystolithiasis [3, 24, 43, 44]. Similarly, in our study secondary choledocholithiasis was found in $26.3 \%$ patients with lithiasis in group $A$, "and in $8.4 \%$ of patients with lithiasis in group $B$. The difference between these groups was significant $(p=0.0184)$. 
Our findings confirm a strong association between bile duct stones and DD. This is present both in subjects with common bile duct stones as primary choledocholithiasis and as secondary choledocholithiasis among patients with lithiasis in group $A$ and group $B$. However, this difference was not significant between patients with lithiasis of both groups compared with all patients of both groups.

Consistent with our findings, Li et al. [23] also report a particularly close correlation between DD and choledocholithiasis after cholecystectomy.

A recent study by Bruno et al. [5] confirmed an association between diverticula and choledocholithiasis, cholangitis and common bile duct dilatation in an endoscopic ultrasound study of the prevalence of DD. In addition, no significant association was found between the presence of DD and acute, recurrent or chronic pancreatitis, as in the present study.

Khan et al. [17] present a case of Lemmel's syndrome, defined as obstructive jaundice, caused by DD in absence of choledocholithiasis or tumour $[1,13,14]$. Diagnosing Lemmel's syndrome is often challenging; to avoid delays in diagnosis and management, a side-viewing endoscope is used on patients with DD during ERCP. This approach is considered to be the gold-standard diagnostic test and diverticulectomy remains the standard of care.

The most frequent complications associated with ERCP are bleeding and severe acute pancreatitis $[3,4,8,25,29]$. The presence of a diverticulum did not affect the frequency of ERCP complication, which indicates that the location of the papilla close to the diverticulum does not hinder its catheterisation. In $31.8 \%$ patients with the papilla located near to the diverticulum, no other pathology was detected, which could explain the occurrence of the ailments reported by our patients. Chiang et al. [9] report a lower percentage of such patients (11\%). However, unlike previous studies, our findings indicate that the type of diverticulum was not associated with the frequency of any specific complaints.

\section{Limitations of the study}

The present study has one key limitation: it was not possible to exclude the likelihood of the presence of microlithiasis among some of the patients.

\section{CONCLUSIONS}

Gallstones were more common in the group of patients with periampullary diverticula than in the control group; however, the difference was not significant. In patients with diverticula, this frequency is similar in men and women.

In patients with diverticula, the most common localization of the diverticulum is next to the major duodenal papilla (type III).

Duodenal diverticula can have a significant influence on the frequency of pathologies, especially in the area of the bile duct. Patients with papilla in the diverticulum who underwent cholecystectomy were found to be more prone to developing lithiasis.

It is possible that in the presence of $\mathrm{DD}$, bile buildup and thickening may possibly lead to the development of gallstones and biliary duct stones.

The results also suggest that the presence of DD in the area of major duodenal papilla, accompanied by choledocholithiasis, is similar in both sexes; however, the type of diverticulum is not related to the incidence of any specific complaint.

\section{REFERENCES}

1. Agúndez MC, Guerra DL, Pérez JF, et al. Síndrome de Lemmel: ictericia obstructiva secundaria a divertículo duodenal. Cir Esp. 2017; 95(9): 550-551, doi: 10.1016/j.ciresp.2017.02.003.

2. Altonbary AY, Bahgat MH. Endoscopic retrograde cholangiopancreatography in periampullary diverticulum: The challenge of cannulation. World J Gastrointest Endosc. 2016; 8(6): 282-287, doi: 10.4253/wjge.v8.i6.282, indexed in Pubmed: 27014423.

3. Bergman S, Koumanis JD, Stein LA, et al. Duodenal diverticulum with retroperitoneal perforation. Can J Surg. 2005; 48(4): 332-336.

4. Boix J, Lorenzo-Zúñiga $V$, Añaños $F$, et al. Impact of periampullary duodenal diverticula at endoscopic retrograde cholangiopancreatography: a proposed classification of periampullary duodenal diverticula. Surg Laparosc Endosc Percutan Tech. 2006; 16(4): 208-211, doi: 10.1097/00129689200608000-00002, indexed in Pubmed: 16921297.

5. Bruno $M$, Ribaldone $D$, Fasulo $R$, et al. Is there a link between periampullary diverticula and biliopancreatic disease? An EUS approach to answer the question. Dig Liver Dis. 2018; 50(9): 925-930, doi: 10.1016/j.dld.2018.07.034.

6. Branco C, Carneiro T, Luis D, et al. Perforated duodenal diverticulum: a rare complication in a common condition. BMJ Case Rep. 2017; 2017, doi: 10.1136/bcr-2017219881, indexed in Pubmed: 28647710.

7. Chandy G, Hart WJ, Roberts-Thomson IC. An analysis of the relationship between bile duct stones and periampullary duodenal diverticula. J Gastroenterol Hepatol. 1997; 12(1): 29-33, doi: 10.1111/j.1440-1746.1997.tb00341.x, indexed in Pubmed: 9076619.

8. Chen L, Xia L, Lu Y, et al. Influence of periampullary diverticulum on the occurrence of pancreaticobiliary diseases and outcomes of endoscopic retrograde cholangiopancreatography. Eur J Gastroenterol Hepatol. 2017; 29(1): 105-111, doi: 10.1097/MEG.0000000000000744, indexed in Pubmed: 27606949. 
9. Chiang TH, Lee YC, Chiu HM, et al. Endoscopic therapeutics for patients with cholangitis caused by the juxtapapillary duodenal diverticulum. Hepatogastroenterology. 2006; 53(70): 501-505.

10. Christoforidis E, Goulimaris I, Kanellos I, et al. The role of juxtapapillary duodenal diverticula in biliary stone disease. Gastrointest Endosc. 2002; 55(4): 543-547, doi: 10.1067/mge.2002.122615, indexed in Pubmed: 11923769.

11. Egawa N, Kamisawa T, Tu Y, et al. The role of juxtapapillary duodenal diverticulum in the formation of gallbladder stones. Hepatogastroenterology. 1998; 45(22): 917-920, indexed in Pubmed: 9755980.

12. Farcas I, Patko A. The clinical significance of juxtapapillary diverticula: endoscopic and radiological study [abstract in English]. Wien Klin Wochenschr. 1981; 93(9): 296-303, indexed in Pubmed: 6789558.

13. Frauenfelder G, Maraziti A, Ciccone V, et al. Computed Tomography Imaging in Lemmel Syndrome: A Report of Two Cases. J Clin Imaging Sci. 2019; 9: 23, doi: 10.25259/ JCIS-17-2019, indexed in Pubmed: 31448174.

14. Kang HS, Hyun JJ, Kim SY, et al. Lemmel's syndrome, an unusual cause of abdominal pain and jaundice by impacted intradiverticular enterolith: case report. J Korean Med Sci. 2014; 29(6): 874-878, doi: 10.3346/jkms.2014.29.6.874, indexed in Pubmed: 24932093.

15. Katsinelos P, Chatzimavroudis G, Tziomalos K, et al. Impact of periampullary diverticula on the outcome and fluoroscopy time in endoscopic retrograde cholangiopancreatography. Hepatobiliary Pancreat Dis Int. 2013; 12(4): 408-414, doi: 10.1016/s1499-3872(13)60063-6.

16. Kennedy RH, Thompson MH. Are duodenal diverticula associated with choledocholithiasis? Gut. 1988; 29(7): 1003-1006, doi: 10.1136/gut.29.7.1003, indexed in Pubmed: 3135249.

17. Khan BA, Khan SH, Sharma A. Lemmel's syndrome: a rare cause of obstructive jaundice secondary to periampullary diverticulum. Eur J Case Rep Intern Med. 2017; 4(6): 000632, doi: 10.12890/2017_000632, indexed in Pubmed: 30755952.

18. Kim DI, Kim MH, Lee SK, et al. Risk factors for recurrence of primary bile duct stones after endoscopic biliary sphincterotomy. Gastrointest Endosc. 2001; 54(1): 42-48, doi: 10.1067/mge.2001.115335, indexed in Pubmed: 11427840 .

19. Kim CW, Chang JH, Kim JiH, et al. Size and type of periampullary duodenal diverticula are associated with bile duct diameter and recurrence of bile duct stones. J Gastroenterol Hepatol. 2013; 28(5): 893-898, doi: 10.1111/ jgh.12184, indexed in Pubmed: 23432035.

20. Ko KS, Kim SH, Kim HC, et al. Juxtapapillary duodenal diverticula risk development and recurrence of biliary stone. J Korean Med Sci. 2012; 27(7): 772-776, doi: 10.3346/jkms.2012.27.7.772, indexed in Pubmed: 22787373.

21. Li $X$, Zhu $K$, Zhang $L$, et al. Periampullary diverticulum may be an important factor for the occurrence and recurrence of bile duct stones. World J Surg. 2012; 36(11): 2666-2669, doi: 10.1007/s00268-012-1716-8, indexed in Pubmed: 22911215.
22. Lee JJ, Brahm G, Bruni SG, et al. Biliary dilatation in the presence of a periampullary duodenal diverticulum. Br J Radiol. 2015; 88(1053): 20150149, doi: 10.1259/ bjr.20150149, indexed in Pubmed: 26133074.

23. Li X, Zhu K, Zhang L, et al. Periampullary diverticulum may be an important factor for the occurrence and recurrence of bile duct stones. World J Surg. 2012; 36(11): 2666-2669, doi: 10.1007/s00268-012-1716-8, indexed in Pubmed: 22911215.

24. Linde $K$, van der Linden GH, Beukers $R$, et al. Food impaction in a duodenal diverticulum as an unusual cause of biliary obstruction: case reports and review of the literature. Eur J Gastroenterol Hepatol. 1997; 9(6): 635-639, doi: 10.1097/00042737-199706000-00021, indexed in Pubmed: 9222744.

25. Linde K, van der Linden GH, Beukers R. Periampullary diverticula: consequences of failed ERCP. Ann R Coll Surg Engl. 1998; 80: 326-331, indexed in Pubmed: 9849331.

26. Lobo DN, Balfour TW, Iftikhar SY, et al. Periampullary diverticula and pancreaticobiliary disease. Br J Surg. 1999; 86(5): 588-597, doi: 10.1046/j.1365-2168.1999.01121.x, indexed in Pubmed: 10361174.

27. Loffeld RJ, Dekkers PEP. The impact of duodenal diverticuli and the execution of endoscopic retrograde cholangiopancreaticography. Int Sch Res Notices. 2016; 2016: 5026289, doi: 10.1155/2016/5026289, indexed in Pubmed: 27882342.

28. Major P, Dembiński M, Winiarski M, et al. A periampullary duodenal diverticula in patient with choledocholithiasis: single endoscopic center experience. Pol Przegl Chir. 2016; 88(6): 328-333, doi: 10.1515/pjs-2016-0072, indexed in Pubmed: 28141552.

29. Mohammad Alizadeh AH, Afzali ES, Shahnazi A, et al. ERCP features and outcome in patients with periampullary duodenal diverticulum. ISRN Gastroenterol. 2013; 2013: 217261, doi: 10.1155/2013/217261, indexed in Pubmed: 23984079.

30. Örmeci N, Deda X, Kalkan Ç, et al. Impact of Periampullary Diverticula on Bile Duct Stones and Ampullary Carcinoma. Euroasian J Hepatogastroenterol. 2016; 6(1): 31-34, doi: 10.5005/jp-journals-10018-1162, indexed in Pubmed: 29201721.

31. Ozogul B, Ozturk G, Kisaoglu A, et al. The clinical importance of different localizations of the papilla associated with juxtapapillary duodenal diverticula. Can J Surg. 2014; 57(5): 337-341, doi: 10.1503/cjs.021113, indexed in Pubmed: 25265108.

32. Pearl MS, Hill MC, Zeman RK. CT findings in duodenal diverticulitis. Am J Roentgenol. 2006; 187(4): W392-W395, doi: 10.2214/AJR.06.0215, indexed in Pubmed: 16985110.

33. Qi C, Zhaodong L, Shengwei L, et al. Diagnosis and treatment of juxta-ampullary duodenal diverticulum. Clin Invest Med. 2010; 33(5): E298-E303, doi: 10.25011/cim. v33i5.14355, indexed in Pubmed: 20926036.

34. Rajnakova A, Goh PM, Ngoi SS, et al. ERCP in patients with periampullary diverticulum. Hepatogastroenterology. 2003; 50(51): 625-628, indexed in Pubmed: 12828047. 
35. Song ME, Chung MJ, Lee DJ, et al. Cholecystectomy for prevention of recurrence after endoscopic clearance of bile duct stones in Korea. Yonsei Med J. 2016; 57(1): 132-137, doi: 10.3349/ymj.2016.57.1.132, indexed in Pubmed: 26632393.

36. Sun Z, Bo W, Jiang P, et al. Different types of periampullary duodenal diverticula are associated with occurrence and recurrence of bile duct stones: a case-control study from a Chinese Center. Gastroenterol Res Pract. 2016; 2016: 9381759, doi: 10.1155/2016/9381759, indexed in Pubmed: 27143965.

37. Tham TCK, Kelly M. Association of periampullary duodenal diverticula with bile duct stones and with technical success of endoscopic retrograde cholangiopancreatography. Endoscopy. 2004; 36(12): 1050-1053, doi: 10.1055/s2004-826043, indexed in Pubmed: 15578293.

38. Tomizawa M, Shinozaki F, Motoyoshi Y, et al. Association between juxtapapillary diverticulum and acute cholangitis determined using laboratory data. Clin Exp Gastroenterol. 2014; 7: 447-451, doi: 10.2147/CEG.S71539, indexed in Pubmed: 25429235.

39. Tomizawa M, Shinozaki F, Hasegawa R, et al. Comparison of acute cholangitis with or without common bile duct dilatation. Exp Ther Med. 2017; 13(6): 3497-3502, doi: 10.3892/etm.2017.4401.
40. Wijarnpreecha K, Panjawatanan P, Manatsathit W, et al. Association between juxtapapillary duodenal diverticula and risk of choledocholithiasis: a systematic review and meta-analysis. J Gastrointest Surg. 2018; 22(12): 2167-2176, doi: 10.1007/s11605-018-3865-z, indexed in Pubmed: 30022443.

41. Yildirgan MI, Başoğlu M, Yilmaz I, et al. Periampullary diverticula causing pancreaticobiliary disease. Dig Dis Sci. 2004; 49(11-12): 1943-1945, doi: 10.1007/s10620-0049597-9, indexed in Pubmed: 15628730.

42. Zajac A, Solecki R, Kruszyna T, et al. Duodenal diverticula and choledocholithiasis in own material. [abstract in English]. Przegl Lek. 2005; 62(12): 1398-1400, indexed in Pubmed: 16786758.

43. Zippi M, Traversa G, Pica R, et al. Efficacy and safety of endoscopic retrograde cholangiopancreatography (ERCP) performed in patients with Periampullary duodenal diverticula (PAD). Clin Ter. 2014; 165(4): e291-e294, doi: 10.7417/CT.2014.1745, indexed in Pubmed: 25203345.

44. Zoepf T, Zoepf DS, Arnold J. Juxtapapillary duodenal diverticula and biliopancreatic disease: analysis of 350 patients. Gastrointest Endosc. 2001; 54(1): 56-61, doi: 10.1067/mge.2001.115334, indexed in Pubmed: 11427842 . 